\title{
On the active deformations of hybrid specimens
}

\author{
Mario Rosario Chiarelli, Vincenzo Binante, Stefano Botturi and Andrea Massai \\ Department of Civil and Industrial Engineering, University of Pisa, Pisa, Italy \\ Fan Kunzmann \\ Smart Material GmbH, Dresden, Germany \\ Angelo Colbertaldo \\ iChrome Ltd, Bristol, UK, and \\ Diego Giuseppe Romano \\ Piaggio Aero Industries SpA, Capua, Italy
}

\begin{abstract}
Purpose - The purpose of this study concerns numerical studies and experimental validation of the mechanical behavior of hybrid specimens. These kinds of composite specimens are made up of thin carbon and glass substrates on which some Macro Fiber Composite ${ }^{\circledR}$ (MFC) piezoelectric patches are glued. A proper design and manufacturing of the hybrid specimens as well as testing activities have been performed. The research activity has been carried out under the FutureWings project, funded by the European Commission within the 7th Framework.

Design/methodology/approach - The paper describes the basic assumptions made to define specimen geometries and to carry out experimental tests. Finite element (FE) results and experimental data (laser technique measurements) have been compared: it shows very good agreement for the displacements' distribution along the specimens.

Findings - Within the objectives of the project, the study of passive and active deformation characteristics of the hybrid composite material has provided reference technical data and has allowed for the correct adaptation of the FE models. More in particular, using the hybrid specimens, both the bending deformations and the torsion deformations have been studied.

Practical implications - The deformation capability of the hybrid specimens will be used in the development of prototypical three-dimensional structures, that, through the electrical control of the MFC patches, will be able to change the curvature of their cross section or will be able to change the angle of torsion along their longitudinal axis.

Originality/value - The design of nonstandard specimens and the tests executed represent a novelty in the field of structures using piezoelectric actuators. The numerical and experimental data of the present research constitute a small step forward in the field of smart materials technology.
\end{abstract}

Keywords Finite element method, Composite substrate, Hybrid specimens, Laser technique, Macro Fiber Composite ${ }^{\circledR}$

Paper type Research paper

\section{Nomenclature}

\section{Definitions, Acronyms and Abbreviations}

$$
\begin{array}{ll}
\mathrm{Ei} & =\text { Young's modulus in the direction } \mathrm{i} \\
\mathrm{Gij} & =\text { Shear modulus in the } \mathrm{i}-\mathrm{j} \text { plane } \\
\nu \mathrm{ij} & =\text { Poisson ratio in the } \mathrm{i}-\mathrm{j} \text { plane } \\
\mathrm{FE} & =\text { Finite element } \\
\mathrm{FEM} & =\text { Finite element method } \\
\mathrm{FEA} & =\text { Finite element analysis } \\
\mathrm{GUI} & =\text { Graphical user interface } \\
\mathrm{MFC} & =\text { Macro Fiber Composite }{ }^{\circledR} \\
\text { ppm } & =\text { Part per million }
\end{array}
$$

The current issue and full text archive of this journal is available on Emerald Insight at: www.emeraldinsight.com/1748-8842.htm

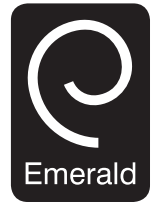

Aircraft Engineering and Aerospace Technology: An International Journal 88/5 (2016) 676-687

Emerald Group Publishing Limited [ISSN 1748-8842]

[DOI 10.1108/AEAT-02-2015-0058]

\section{Introduction}

A research project is aimed at the theoretical study, and preliminary experimental validation, of a wing structure having the capability of changing its aerodynamic shape through the use of a new type of hybrid materials, which are based on the implementation of layers of piezoelectric fibers into laminates of composite materials. Such a wing will be capable of deforming on command, which means that it will be possible to modify aircraft aerodynamic loads without the installation of traditional control surfaces (ailerons, etc). in the wings.
(C) Mario Chiarelli, Vincenczo Binante, Stefano Botturi, Andrea Massai, Jan Kunzmann, Angelo Colbertaldo, Diego Romano. Published by Emerald Group Publishing Limited. This article is published under the Creative Commons Attribution (CC BY 3.0) licence. Anyone may reproduce, distribute, translate and create derivative works of this article (for both commercial and non-commercial purposes), subject to full attribution to the original publication and authors. The full terms of this licence may be seen at http://creativecommons.org/licences/by/3.0/legalcode.

Received 27 February 2015

Accepted 22 May 2016 
A deformed shape of the wing will be obtained quasi-statically, activating the piezoelectric layers, giving us the possibility of using a low electric power level. It is therefore expected that very low current intensity values and medium voltage values will be necessary to command a futuristic wing structure.

A small-scale model of the futuristic structure will be manufactured in the development of the project. It will be realized through a proper design of the hybrid active composite laminate, based on technical know-how gained testing ad hoc specimens of the same material and setting up calculation models. Mechanical tests on this model will be carried out to verify the technical feasibility of the futuristic structure concept.

In a technical but futuristic application of this technology, as a first result, it can be said that to deform complex and robust aero structures, we would need to get large deformations actuators (for example, providing maximum elongations at least equal to 10,000 or $15,000 \mathrm{ppm}$ ). Anyway, in the project, a very important amount of work has been dedicated to the simulation of realistic hybrid specimens made up of composite materials and Macro Fiber Composite ${ }^{\circledR}$ (MFC) patches (Smart Material Corporation, 2013). Bending and torsion specimens have been studied in detail by means of non-linear finite element analyses (FEA). At the end of these analyses, detailed drawings of the specimens have been prepared to proceed with the manufacturing and testing phases.

In the technical literature exist several works that aimed to study the piezoelectric applications (Bilgen et al., 2011; Morisghima et al., 2010; Li et al., 2014; Riemenschneider et al., 2004), but these are missing a systematic work to characterize the mechanical behavior of the MFC patches either co-cured in or glued on substrates of composite material.

Further, the literature shows that a large number of researches aimed to the study of static and dynamic performances of active structures equipped with MFC patches (used as sensors and/or actuators): an examination of some research papers has been summarized below.

An interesting work relevant to a sandwich plate undergoing thermal loads including the effects of MFC patches used as actuators can be found in the study by Binette et al. (2009). This work contains a comparison between numerical and experimental data of the lateral deflection of the sandwich plate. A good agreement can be observed between the data and, as done in our work, the finite element (FE) model of the plate has been constructed with three-dimensional solid elements.

Another example of a flexible structure actuated by MFC patches can be found in the study by Schröck et al. (2011a, 2011b). The work shows as a motion planning and a feed-forward control design of a flexible beam can be defined by means of MFC patches used as actuators. In the paper, the dynamic response of the structure under observation has been modelled and measured: the voltage signal applied to the MFC actuators followed typical input histories (step or staircase signal). The beam's tip deflection history, registered using a laser sensor, revealed the presence of hysteresis and creep behavior of the tip deflection/voltage relationship. A control procedure to compensate the hysteresis phenomena under dynamic conditions has been developed and adopted in the paper. Moreover, because of the complexity of the problem, all the results discussed in the paper refer only to a simple model of a flexible beam.

In a recent paper (Sathyanarayana et al., 2013), a numerical and experimental study on MFC patches used as a sensor is provided. Under dynamic conditions, a correlation between the MFC output signal and strain gauge and accelerometer data is discussed. The structure under observation concerns a thin plate made of composite material.

An example of the implementation of MFC as actuators for an active composite wing is provided by Paradies et al. (2009). The paper describes the design and manufacturing process of a wing model with embedded MFC patches which induce torsion deformation to wing profile. A preliminary deformation test of the wing is discussed under aerodynamic effects and the bending moment at the root of the wing has been measured (roll moment). The paper represents an example of the feasibility of morphing wings actuated by means of piezoelectric patches.

Some preliminary data on the fatigue behavior of MFC can be found in the study by Henslee et al. (2012): the effect of temperature on fatigue endurance of MFC used as dynamic actuators has been discussed in the paper. The structure analyzed in the research is a stainless steel beam: tip displacement and strain measurements were monitored as methods of evaluating the performances of the MFC patches. As discussed in the cited paper, some specimens showed fatigue failures because of cracking of piezoelectric fibers and, by increasing the temperature, a strong reduction of the fatigue life of MFC has been observed even if the data shown are not statistically significant because of limited sample availability.

The paper (Chesne et al., 2013) discusses an interesting research activity on the experimental identification of active structures using MFC patches as actuators and polyvinylidene fluoride transducers fully integrated into the structure. The method used in the paper is based on the characterization of the experimental frequency response function (FRF) of the composite structure: through the use of a curve-fitting technique on the FRF, all dynamic data relevant to the structure can be directly estimated without specific information on the shape of the transducers, the transducers location, gluing effects, glass fiber distribution or other technological and/or manufacturing effects.

In a recent paper (Molinari et al., 2015), a compliant adaptable wing with MFC patches implemented as actuators has been designed and preliminarily tested. The paper represents a further and interesting example of the feasibility of morphing wings actuated by means of piezoelectric patches. The structure has been obtained by adopting an optimization procedure for designing the compliant structures which compose the inner parts of the wing. The wing has been studied from an aero-elastic point of view: in other words, the wing supports realistic aerodynamic loads because of flight maneuvers during the numerical analyses.

Finally, in the paper (Rao et al., 2016), the nonlinear constitutive behavior of piezoelectric materials under large applied electric fields has been examined and modelled. The 
results shown are relevant to static cases, and the geometries examined (available in the literature) refer to a cantilever bimorph actuator, a cantilevered composite plate laminated and a cylindrical shell. In all the cases examined, the method proposed provides better results for the lateral displacement distribution compared with other numerical results available in the literature: in other words, the nonlinear effect due to large applied electric fields can be described in a very good manner, and, as a result, it cannot be neglected for the study of the deformation of active piezoelectric structures.

In the present research, hybrid specimens have been manufactured in two different typologies, i.e. with carbon/ epoxy substrates and with glass/epoxy substrates. The piezoelectric actuators made with MFC patches have been glued on both sides of the substrates. The possibility of a co-curing technique was evaluated, but because of the uncertainty of the final thicknesses and the stiffness characteristic of the specimens, it was decided not to use it.

Furthermore, design and manufacturing of two test equipment have been executed; in particular, a system of three linear slides controlled by computer has been realized and assembled. This slides allowed the positioning of the laser sensors used to measure both the initial deformation of the hybrid specimens and the deformations induced by the piezoelectric actuators during the tests. A prototype of a novel version of the electronic control system of the piezo-patches has also been produced: in particular, a high voltage amplifier with six independent channels has been manufactured for this purpose.

Deformation tests of the hybrid specimens have been carried out: the comparison between experimental and numerical results shows very good agreement, confirming the validity of the numerical models developed in the project.

\section{The hybrid specimens}

For the first campaign of experimental tests, two main types of specimens have been considered. Torsion specimen: composite laminate with six MFC patches bonded on the upper and lower surfaces. The MFC patches have $+45^{\circ} /-45^{\circ}$ fiber orientation with respect to the length of the specimen. Bending specimen: composite laminate with six MFC patches bonded on the upper and lower surface. In this case, the MFC patches have $0^{\circ}$ fiber orientation with respect to the length of the specimen.

Different composite materials have been considered for the laminate of the two types of specimens: the graphite-fiber/ epoxy-resin laminate KGBX2508 and the glass-fiber/ epoxy-resin laminate GGBX2808 (Krempel GmbH, 2014). Each laminate consists of four fabric plies with two different fiber orientations: $0 \% 190^{\circ}$ and $+45^{\circ} / 45^{\circ}$ with respect to the length of the specimen. The ply-stacking sequences are reported in Table I.

The MFC types used for test specimens (Figure 1) are M8528-P1 for the bending specimens and M8557-F1 for the torsion specimens (Figure 2). In the numerical models, the d33 value, corresponding to the mechanical-electrical coupling effect for these MFC types has been inserted in the field corresponding to the $\mathrm{d} 31$ constant. The reason concerns the application of the voltage boundary conditions: the electric potential gradient is applied through the thickness of the patch
Table I Ply stacking of the substrates material

\begin{tabular}{lcccc}
\hline Ply N. & $\begin{array}{c}\text { Sequence } \\
\text { N. 1 }\end{array}$ & $\begin{array}{c}\text { Sequence } \\
\text { N. 2 }\end{array}$ & $\begin{array}{c}\text { Sequence } \\
\text { N. 3 }\end{array}$ & $\begin{array}{c}\text { Sequence } \\
\text { N. 4 }\end{array}$ \\
\hline $\mathbf{1}$ & $+45 /-45$ & $0 / 90$ & $0 / 90$ & $+45 /-45$ \\
$\mathbf{2}$ & $0 / 90$ & $+45 /-45$ & $0 / 90$ & $+45 /-45$ \\
$\mathbf{3}$ & $0 / 90$ & $+45 /-45$ & $0 / 90$ & $+45 /-45$ \\
$\mathbf{4}$ & $+45 /-45$ & $0 / 90$ & $0 / 90$ & $+45 /-45$ \\
\hline
\end{tabular}

(direction 3), but the strain remains in-plane (direction 1) (Figure 3).

The four ply-stacking sequences have been considered for finite element method (FEM) analyses, but only Sequences N.1 and N.2 have been considered for the manufacturing of the specimens.

The torsion specimen has been designed to obtain an almost pure torsion effect on a substrate laminate. The experimental tests should provide information on the deformation of the specimen along its length, maximum displacement at the tip section and torsion angle associated, when an electric potential that is applied on the MFC patches. Also, structural loads, in this case, a torque moment, should be applied to obtain information on the static or quasi-static response of the specimen.

The dimensions for the components of the torsion specimen are: substrate laminate $=400 \times 80 \times 1 \mathrm{~mm}$ (four twill fabrics), M8557-F1 $=105 \times 64 \times 0.3 \mathrm{~mm}$ (active area $=85 \times 57 \mathrm{~mm}$ ). In the model, a bonding resin layer with $0.075 \mathrm{~mm}$ of thickness between the MFC patches and the substrate laminate has been considered. The thickness of each twill fabric is $0.25 \mathrm{~mm}$.

The dimensions for the components of the bending specimen are: substrate laminate $=400 \times 45 \times 1 \mathrm{~mm}$ (four twill fabrics), $\mathrm{M} 8528-\mathrm{P} 1=103 \times 35 \times 0.3 \mathrm{~mm}$ (active area $=85 \times 28 \mathrm{~mm}$ ). As for the model of the torsion specimen, a bonding resin layer with $0.075 \mathrm{~mm}$ of thickness between the MFC patches and the substrate laminate has been considered. The thickness of each twill fabric is still $0.25 \mathrm{~mm}$

For the substrate materials, graphite/epoxy and a glass/epoxy composites have been adopted. The complete 3D material data used in the model are summarized in Table II. As an example, in Figure 4 the manufactured torsion specimens used in the experimental activity are shown.

\section{Finite element analyses}

For simplicity, the grips for locking the specimen have not been modeled: the FEM model of the specimens has been clamped on the short side section of the substrate laminate $(Z=0$, blue axis in Figures 1 and 2); thus, the nodal displacement is zero in this section.

Quadratic hexahedral brick elements, with full integration method, have been used for the modeling of the specimen, the Abaqus ${ }^{\circledR}$ FE code has been used (Dassault Systemes, 2013): C3D20 elements for substrate twill fabrics, bonding resin and MFC passive volumes; C3D20E piezoelectric elements for MFC active volumes.

The total number of elements is about 4,200. Geometric non-linearity (large displacements) option has been activated for these analyses. The maximum operational positive voltage for the adopted MFC is $1,500 \mathrm{~V}$. The results relevant to bending specimens will be discussed first, then those relevant to torsion samples. 
Figure 1 Torsion and bending specimens
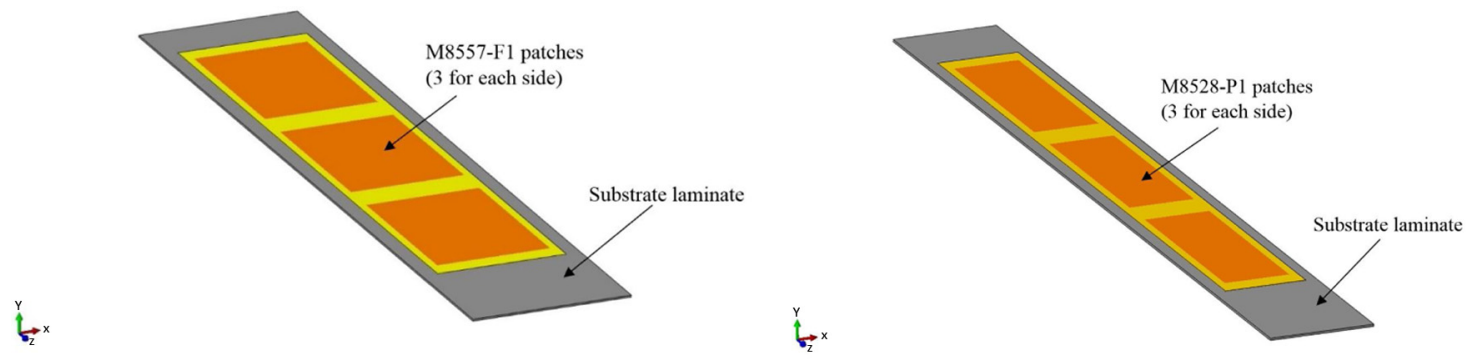

Note: FE geometries

Figure 2 MFC types and fiber orientation
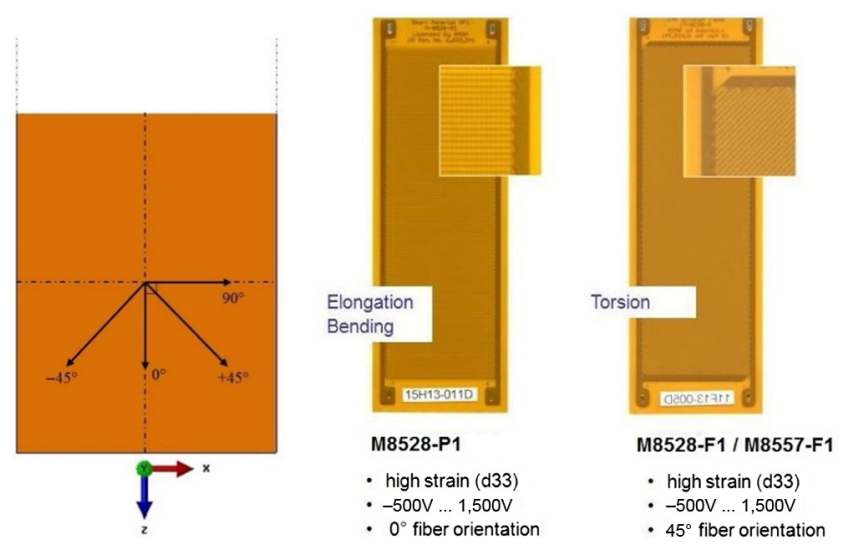

Figure 3 Method used to apply the voltage loading conditions to the active volumes

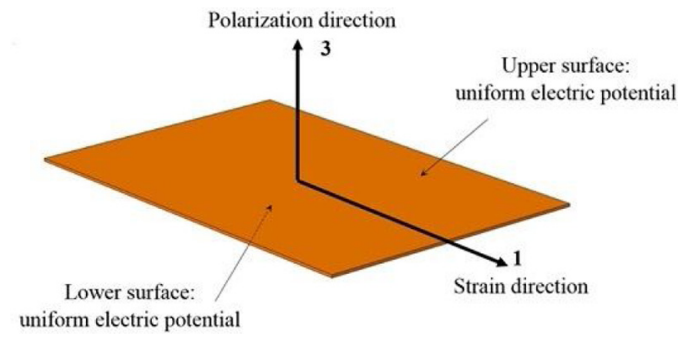

Bending specimens

Several FEAs have been carried out with the aim to estimate the maximum bending attainable by stressing the MFC piezoelectric patches; for this purpose, the influence of the substrate and its composite lay-up on the bending stiffness of the specimen plays an important role.

Table III shows the vertical displacement calculated at the free end of a hybrid specimen made up of graphite/ epoxy laminated substrate, and for each ply-stacking sequence. In the second column of Table III, the results have been obtained by supplying a positive voltage equal to $500 \mathrm{~V}$ to the upper MFC patches, and a negative one equal to $-500 \mathrm{~V}$ to the lower MFC patches; the last column of Table III shows the results obtained by supplying the maximum operating voltages. As shown in Table III, the ply-stacking Sequences 2 and 3 furnish a higher bending stiffness than the other ones; as an example, Figure 5 shows the deformed shape of the sample characterized by the ply-stacking Sequence 1.

Table IV shows the vertical displacement calculated at the free end of a hybrid specimen made up of glass/epoxy laminated substrate, for each ply-stacking sequence and two voltage conditions; the second column shows the results obtained by supplying a voltage equal to $+500 \mathrm{~V}$ and $-500 \mathrm{~V}$ to the upper and lower MFC patches, respectively. Last column of Table IV shows the results relevant to the maximum operating voltages applied to the MFC patches. Unlike the graphite/epoxy laminate, the bending stiffness is less sensitive to a particular ply-stacking sequence of the substrate.

Table II Material data

\begin{tabular}{|c|c|c|c|c|c|}
\hline Engineering constants & Graphite/Epoxy substrate & Glass/Epoxy substrate & Bonding resin & Kapton & MFC active area \\
\hline E1 [GPa] & 67.07 & 25.27 & 4 & 2.5 & 30.34 \\
\hline E2 [GPa] & 67.07 & 25.27 & & & 15.86 \\
\hline E3 [GPa] & 67.07 & 25.27 & & & 15.86 \\
\hline$\nu 12$ & 0.042 & 0.119 & 0.4 & 0.34 & 0.31 \\
\hline$\nu 13$ & 0.042 & 0.119 & & & 0.16 \\
\hline$\nu 23$ & 0.042 & 0.119 & & & 0.16 \\
\hline G12 [GPa] & 4.78 & 4.83 & & & 5.51 \\
\hline G13 [GPa] & 4.78 & 4.83 & & & 5.51 \\
\hline G23 [GPa] & 4.78 & 4.83 & & & 5.51 \\
\hline Density $\left[\mathrm{kg} / \mathrm{m}^{\wedge} 3\right]$ & 1,852 & 2,273 & & & 5,440 \\
\hline Dielectric [F/m] & & & & & $\epsilon_{\mathrm{ii}}=1.64 \mathrm{e}-8$ \\
\hline Piezoelectric [m/V] & & & & & $\mathrm{d} 31=4.6 \mathrm{e}-10$ \\
\hline
\end{tabular}


Figure 4 Torsion specimens

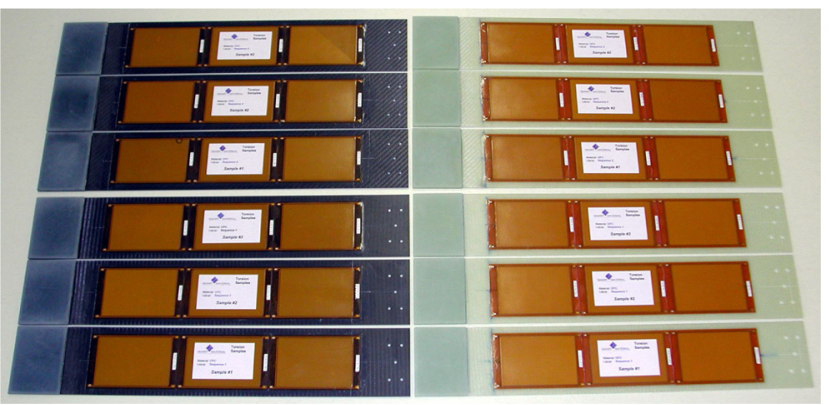

Table III Vertical displacement at the free end of a bending specimen with graphite/epoxy substrate

\begin{tabular}{lcc}
\hline $\begin{array}{l}\text { Stacking sequence } \\
\text { Id }\end{array}$ & $\begin{array}{c}\text { Calculated vertical displacement at the } \\
\text { free end of the sample [mm] } \\
\text { Voltage } \\
+500 /-500\end{array}$ & $\begin{array}{c}\text { Voltage } \\
+1,500 /-500 ~ V\end{array}$ \\
\hline $\mathbf{1}$ & 22.82 & 44.71 \\
$\mathbf{3}$ & 17.25 & 34.36 \\
$\mathbf{4}$ & 16.76 & 33.42 \\
\hline
\end{tabular}

Figure 5 Bending specimen with graphite/epoxy substrate stacking Sequence 1, $+1,500 \mathrm{~V} /-500 \mathrm{~V}$ (units: $\mathrm{m}$ )

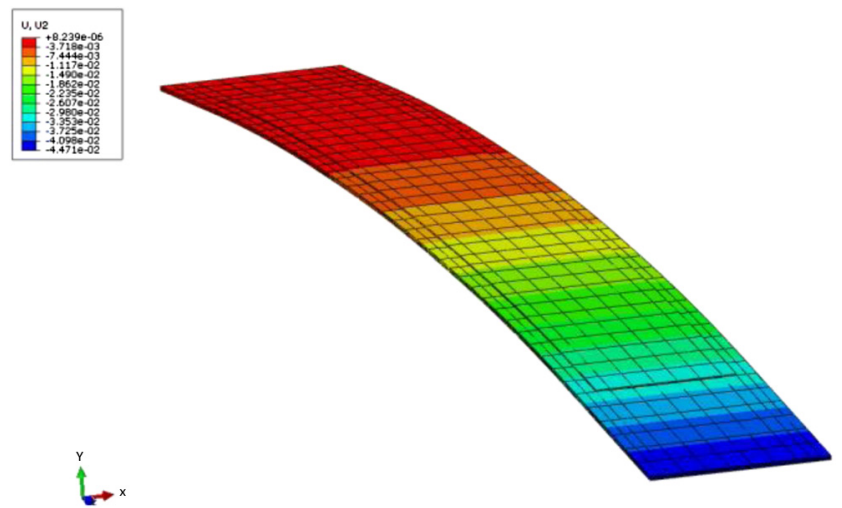

Table IV Vertical displacement at the free end of a bending specimen with glass/epoxy substrate

\begin{tabular}{lcc}
\hline $\begin{array}{l}\text { Stacking sequence } \\
\text { Id }\end{array}$ & $\begin{array}{c}\text { Calculated vertical displacement at the } \\
\text { free end of the sample [mm] } \\
\text { Voltage } \\
+500 /-500 ~ V\end{array}$ & $\begin{array}{c}\text { Voltage } \\
+1,500 /-500 ~ V\end{array}$ \\
\hline 1 & 25.82 & 50.90 \\
2 & 23.78 & 47.14 \\
3 & 23.52 & 46.63 \\
4 & 26.27 & 51.81 \\
\hline
\end{tabular}

Torsion specimens

Also for torsion specimens, several FEAs have been carried out with the aim to estimate the maximum torsion angle attainable by stressing the MFC piezoelectric patches; for this purpose, the influence of the substrate and its composite lay-up on the shear stiffness of the specimen plays an important role.

Table $\mathrm{V}$ shows the vertical displacement and the torsion angle calculated at the free end of a hybrid specimen made up of graphite/epoxy laminated substrate, and for each ply-stacking sequence.

The results have been obtained by supplying the maximum operating voltage (equal to $+1,500 \mathrm{~V}$ ) to all MFC patches; as shown, the ply-stacking Sequences 2 and 3 furnish a larger vertical displacement and rotation than the other ones; in other words, ply-stacking Sequences 1 and 4 supply a higher shear stiffness. As an example, Figure 6 shows the deformed shape of the samples characterized by the ply-stacking Sequence 2.

Table VI shows vertical displacement and rotation calculated at the free end of a torsion specimen made up of glass/epoxy laminated substrate, and for each ply-stacking sequence; also, in these cases, the results have been obtained by supplying the maximum operating voltage to all MFC patches. Like for bending specimens, ply-stacking sequences of the glass/epoxy laminated substrate seem to not affect the shear stiffness of the specimen much.

Table V Vertical displacement and rotation at the free end of torsion specimens with graphite/epoxy substrate

\begin{tabular}{|c|c|c|}
\hline \multirow[b]{2}{*}{$\begin{array}{l}\text { Stacking sequence } \\
\text { Id }\end{array}$} & \multicolumn{2}{|c|}{ Data at the free end of the sample } \\
\hline & $\begin{array}{l}\text { Vertical displacement } \\
{[\mathrm{mm}]}\end{array}$ & $\begin{array}{c}\text { Torsion angle } \\
\text { [deg] }\end{array}$ \\
\hline 1 & 8.18 & 11.56 \\
\hline 2 & 11.07 & 15.47 \\
\hline 3 & 10.96 & 15.32 \\
\hline 4 & 8.68 & 12.24 \\
\hline
\end{tabular}

Figure 6 Torsion specimen with graphite/epoxy substrate stacking Sequence 2, +1,500 V (units: $\mathrm{m}$ )

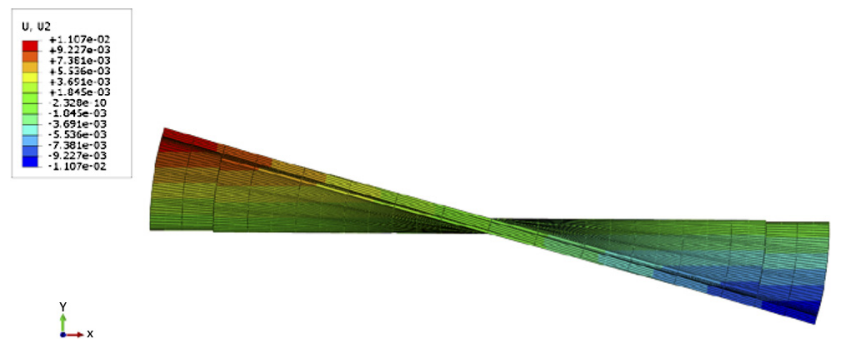

Table VI Vertical displacement and rotation at the free end of torsion specimens with glass/epoxy substrate

\begin{tabular}{|c|c|c|}
\hline \multirow[b]{2}{*}{$\begin{array}{l}\text { Stacking sequence } \\
\text { Id }\end{array}$} & \multicolumn{2}{|c|}{ Data at the free end of the sample } \\
\hline & $\begin{array}{l}\text { Vertical displacement } \\
{[\mathrm{mm}]}\end{array}$ & $\begin{array}{c}\text { Torsion angle } \\
\text { [deg] }\end{array}$ \\
\hline 1 & 11.28 & 15.75 \\
\hline 2 & 12.52 & 17.38 \\
\hline 3 & 12.26 & 17.04 \\
\hline 4 & 11.67 & 16.26 \\
\hline
\end{tabular}




\section{Experimental tests}

Testing equipment for both bending and torsion tests have been designed and manufactured, allowing loading and constraining of specimens; here, a brief description is done regarding the instruments used to measure the deformed shape of the specimen due to structural loads and/or electric loads.

Figures 7 and 8 show the testing equipment used for bending and torsion tests, respectively; three linear stages allow a laser optical displacement sensor to measure the deformed shape of a specimen in several points. As an example, for bending samples, a matrix of 21 measuring points has been used.

The displacement measuring range of the sensor is about 10 $\mathrm{mm}$; more precisely, the measurements range from 20 to $30 \mathrm{~mm}$, with respect to the specimen surface. Because of this short distance, the vertical linear stage becomes necessary for testing.

A LabVIEW $^{\circledR}$ (National Instruments, 2013) user program has been developed to move the linear stages along the three directions; an interactive graphical user interface has been used to move the laser optical sensor, together with the test panel showing the displacement measurement.

As far as the displacement measurements are concerned, the laser optical sensor measures the displacement field in millivolt; typical measurements range from 1 to $5 \mathrm{~V}$. By means of the following relationship:

$$
1 \mathrm{~mm} \equiv 400 \mathrm{mV}
$$

It is possible to evaluate the displacement field in millimeters. Figure 9 shows a typical measurement of the laser optical

Figure 7 Bending test equipment

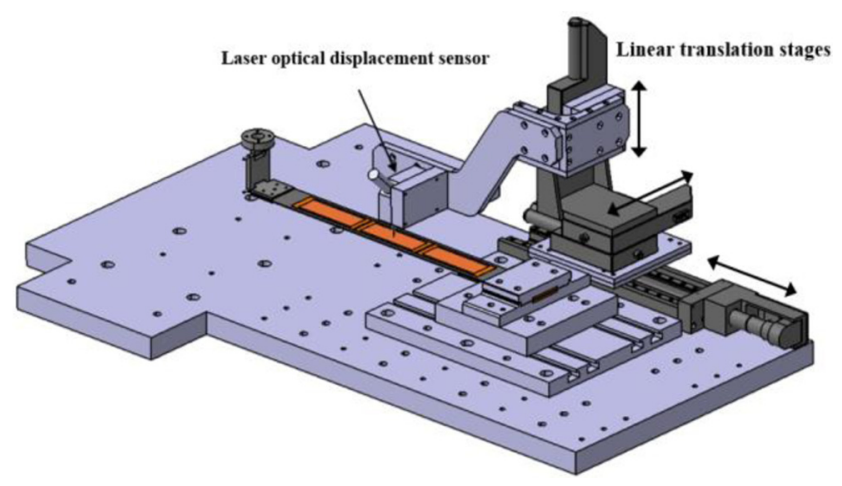

Figure $\mathbf{8}$ Torsion test equipment

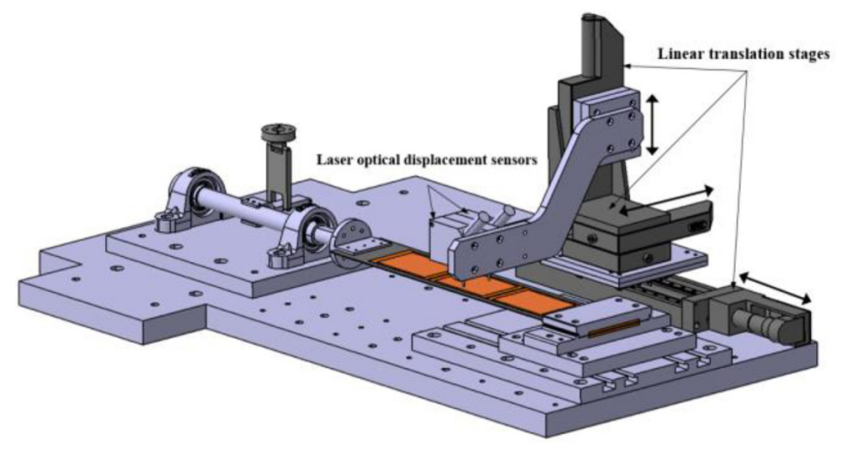

displacement sensor; in particular, the measurements are relevant to a deformed shape of a bending specimen because of its weight.

Electric potential gradients have been applied on MFC piezoelectric patches, by means of a high-voltage amplifier. As an input, the amplifier can get voltages ranging from 0 to $5 \mathrm{~V}$, and, as an output, it gives a voltage ranging from -500 to $1,500 \mathrm{~V}$; more precisely, the input voltage ranging from 0 to $2.5 \mathrm{~V}$ is equivalent to an output voltage ranging from -500 to $0 \mathrm{~V}$, while the input voltage ranging from 2.5 to $5 \mathrm{~V}$ corresponds to an output voltage ranging from 0 to $1,500 \mathrm{~V}$.

\section{The bending tests}

As a mechanical load, testing specimens are subjected to the effect of their weight; in particular, the mass of a bending specimen made up of graphite/epoxy substrate is about $74 \mathrm{~g}$, and the mass of a sample characterized by a glass/epoxy substrate is about $78 \mathrm{~g}$. The mass of torsion specimens is about 137 or $147 \mathrm{~g}$ depending on whether the substrate is made of graphite/epoxy or glass/epoxy, respectively. Therefore, all testing specimens undergo a free bending deformation; in addition, specimens are characterized by an initial shape, which is different from the ideal one. This is due to the manufacturing process. Thus, the initial resulting deformed shape is assumed as the reference one.

In contrast to the reference deformed shape, MFC piezoelectric patches have been loaded in order to promote an opposite bending deformation; this has been done by supplying positive voltages to lower MFC patches and negative ones to the upper MFC patches.

Thus, an input voltage range from 0 to $2.5 \mathrm{~V}$ (equivalent to -500 to $0 \mathrm{~V}$ as output of the high-voltage amplifier) has been applied to the MFC piezoelectric patches which behave as contractors, whereas the voltage range from 2.5 to $5 \mathrm{~V}$ has been used for MFC elongating actuators.

Figure 10, showing an enlarged view of the region close to the clamped section, highlights the deformed shape of a bending sample because of an electric potential gradient applied to the upper and lower MFC patches close to the

Figure 9 A measurement with laser displacement sensor

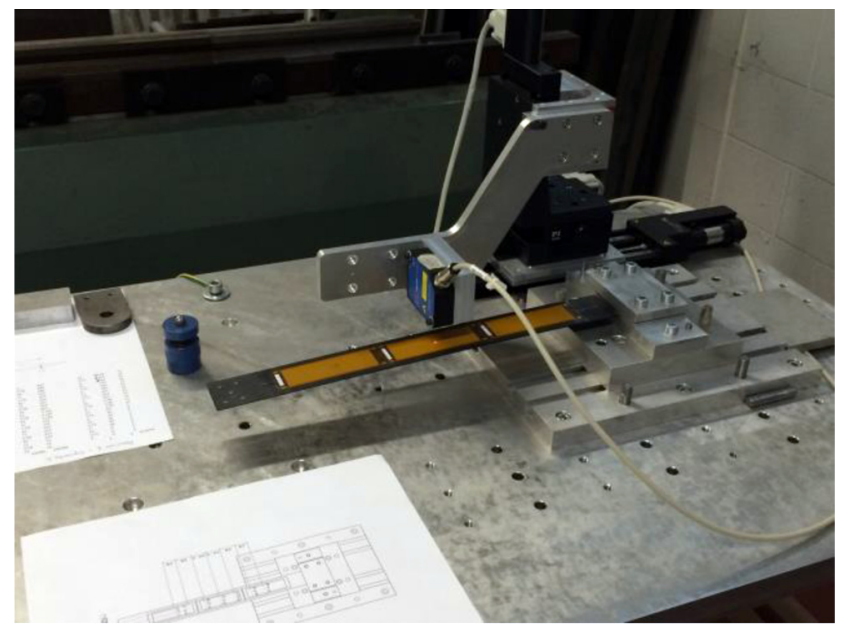

Note: Deformed shape of a bending specimen due to its weight 
Figure 10 Local deformation of sample due to the activated MFC patches close to the clamped section

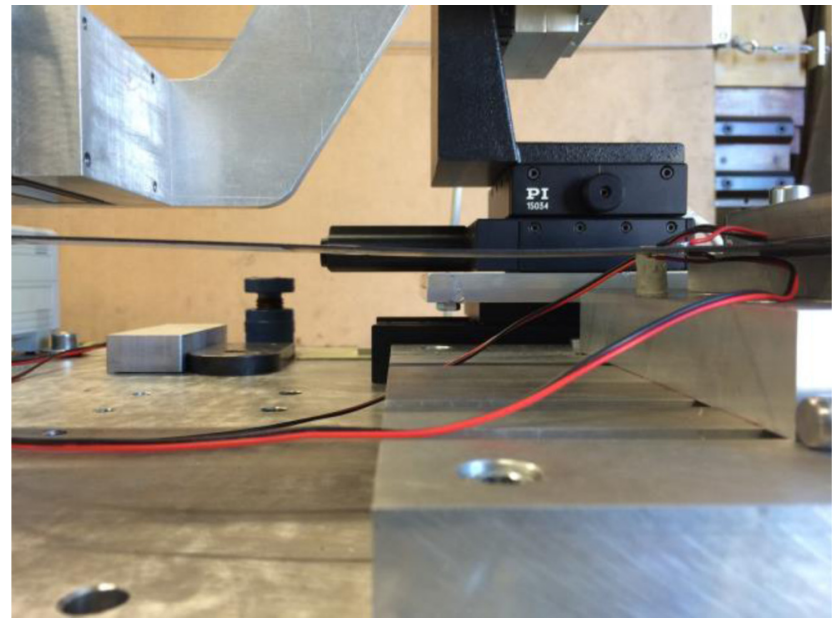

clamped section of the specimen; the upper piezoelectric patch behaves as contracting actuator and the lower patch as elongating ones. Consequently, the bending deformation is opposed to that because of the sample's weight.

The weight effects

As discussed above, 21 measuring points have been chosen to evaluate a deformed shape of the specimen accurately; in particular, seven measurements along the longitudinal axis of the sample, per three in transverse direction. Figure 11 shows the results summarized in the subsequent Table VII.

Table VII shows the points' coordinates with respect to the clamped section, together with the vertical displacement because of the sample's weight. The deformed shape of the specimen has been evaluated as the difference between an initial measured configuration and that measured as a result of the sample's weight.

As shown in the Table VII, for the last three measuring points, no measurement has been possible; this is because of a displacement greater than the allowable measuring range of the sensor.

Figure 11 Graph of displacements for graphite/epoxy bending Sample 1, ply-stacking Sequence 1, due to its weight

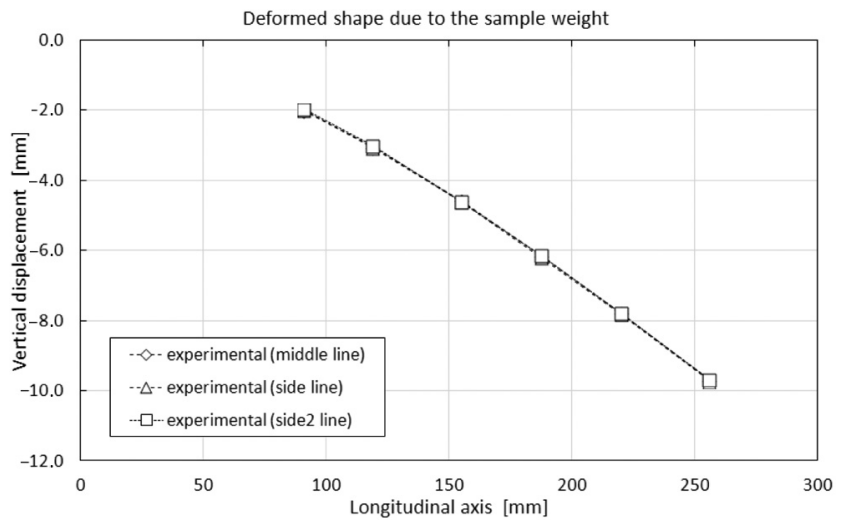

Table VII Displacement of the graphite/epoxy bending Sample 1, ply-stacking Sequence 1, due to its weight

\begin{tabular}{rcrc}
\hline Point Id & $X[\mathrm{~mm}]$ & $Y[\mathrm{~mm}]$ & $\begin{array}{c}\text { Measured vertical } \\
\text { displacement }[\mathrm{mm}]\end{array}$ \\
\hline $\mathbf{1}$ & 91 & -10 & -1.975 \\
2 & 91 & 0 & -2.025 \\
3 & 91 & 10 & -2.000 \\
4 & 119 & -10 & -3.025 \\
5 & 119 & 0 & -3.050 \\
6 & 119 & 10 & -3.075 \\
7 & 155 & -10 & -4.600 \\
8 & 155 & 0 & -4.575 \\
9 & 155 & 10 & -4.600 \\
10 & 187.5 & -10 & -6.125 \\
11 & 187.5 & 0 & -6.150 \\
12 & 187.5 & 10 & -6.200 \\
13 & 220 & -10 & -7.775 \\
14 & 220 & 0 & -7.775 \\
15 & 220 & 10 & -7.800 \\
16 & 256 & -10 & -9.675 \\
17 & 256 & 0 & -9.700 \\
18 & 256 & 10 & -9.725 \\
19 & 285 & -10 & - \\
20 & 285 & 0 & - \\
21 & 285 & 10 & - \\
\hline & & &
\end{tabular}

\section{The voltage effects}

As far as the application of a voltage to MFC piezoelectric patches is concerned, in a first test case, these have activated the MFC Patches 1 and 4, while in a second test case, these have activated the MFC Patches 4, 5 and 6 loaded in parallel (Figure 12). The first test case regards the upper and lower MFC patches close to the clamped section of the sample; it is worth mentioning that for a bending stress, these patches supply a more significant stretch than the others. For this test, three voltage cases have been considered:

$1-250 \mathrm{~V}$ to MFC Patch 1 and $+750 \mathrm{~V}$ to MFC Patch 4.

$2-480 \mathrm{~V}$ to MFC Patch 1 and $+1,440 \mathrm{~V}$ to MFC Patch 4.

$3-400 \mathrm{~V}$ to MFC Patch 1 and $+1,200 \mathrm{~V}$ to MFC Patch 4.

These loading cases have been applied by connecting the MFC 1 to the first channel of the amplifier and the MFC 4 to the second one. As a check of the amplifier, the first and third

Figure 12 Identifier number of the MFC piezoelectric patches

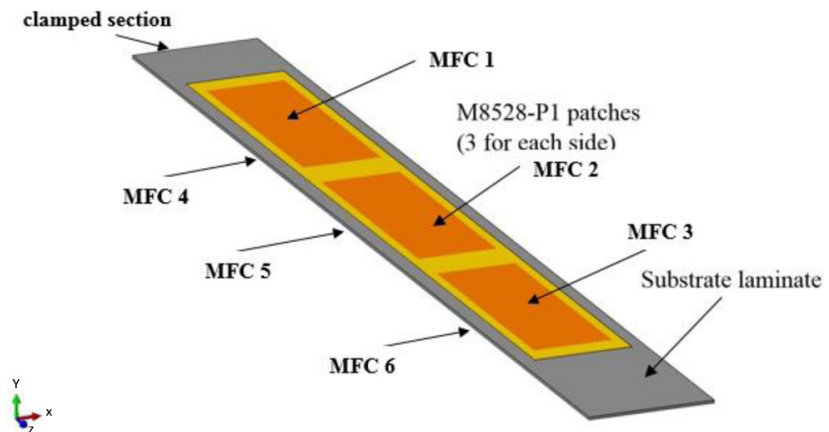


test cases have been repeated by using Channels 3 and 4 . These results are also shown in the graph of Figure 13.

Table VIII shows the detailed data of the third voltage case; also, in this case, a vertical displacement field has been evaluated as the difference between the displacement field measured in correspondence to the reference specimen shape and that measured at the current deformed shape. The results corresponding to the couple of Channels 3 and 4 are very close to those obtained with the couple of Channels 1 and 2 of the high-voltage amplifier.

Figure 13 Displacement field as a result of the third voltage test case

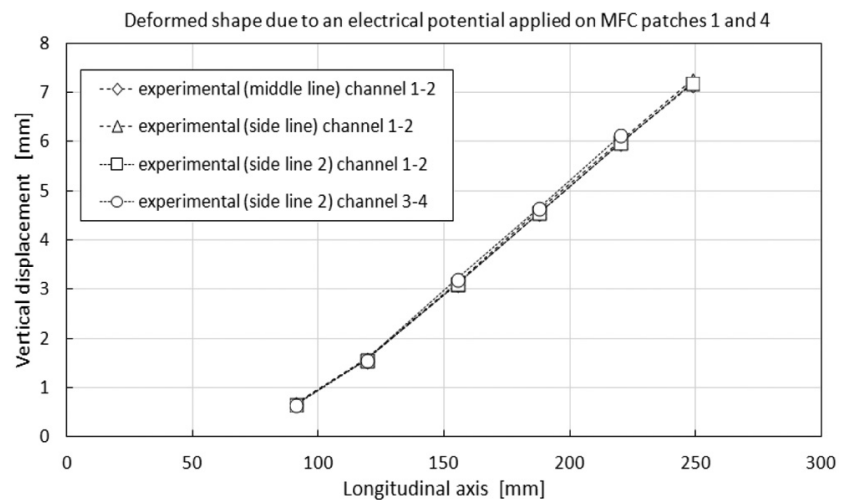

Note: $-400 \mathrm{~V}$ to MFC 1 and $+1,200 \mathrm{~V}$ to MFC 4

Table VIII Displacements for a voltage of $-400 \mathrm{~V}$ applied to MFC 1 and $+1,200 \mathrm{~V}$ applied to MFC 4 (first test case)

\begin{tabular}{|c|c|c|c|c|}
\hline \multirow[b]{2}{*}{ Point id } & \multirow[b]{2}{*}{$X[\mathrm{~mm}]$} & \multirow[b]{2}{*}{$\mathrm{Y}[\mathrm{mm}]$} & \multicolumn{2}{|c|}{$\begin{array}{c}\text { Measured vertical } \\
\text { displacement [mm] } \\
\text { MFC } 1 \text { at }-400 \mathrm{~V}, \mathrm{MFC} 4 \text { at } \\
+1,200 \mathrm{~V}\end{array}$} \\
\hline & & & Channels 1-2 & Channels 3-4 \\
\hline 1 & 91 & -10 & 0.650 & 0.650 \\
\hline 2 & 91 & 0 & 0.675 & \\
\hline 3 & 91 & 10 & 0.675 & \\
\hline 4 & 119 & -10 & 1.550 & 1.550 \\
\hline 5 & 119 & 0 & 1.550 & \\
\hline 6 & 119 & 10 & 1.575 & \\
\hline 7 & 155 & -10 & 3.100 & 3.2 \\
\hline 8 & 155 & 0 & 3.100 & \\
\hline 9 & 155 & 10 & 3.125 & \\
\hline 10 & 187.5 & -10 & 4.550 & 4.650 \\
\hline 11 & 187.5 & 0 & 4.550 & \\
\hline 12 & 187.5 & 10 & 4.600 & \\
\hline 13 & 220 & -10 & 5.975 & \\
\hline 14 & 220 & 0 & 5.975 & \\
\hline 15 & 220 & 10 & 6.000 & \\
\hline 16 & 256 & -10 & 7.175 & \\
\hline 17 & 256 & 0 & 7.175 & \\
\hline 18 & 256 & 10 & 7.250 & \\
\hline 19 & 285 & -10 & - & \\
\hline 20 & 285 & 0 & - & \\
\hline 21 & 285 & 10 & - & \\
\hline
\end{tabular}

As far as the second test case is concerned, all the lower MFC piezoelectric patches (Figure 12) have been stressed, by supplying a voltage equal to $+1,450 \mathrm{~V}$. This has been done by connecting them in parallel to the first channel of the amplifier. Figure 14 and Table IX show the results of this test.

\section{The torsion tests}

Torsion tests have been carried out by constraining both root and tip sections of the sample, as shown in Figure 15; in particular, the constraint of the tip section is equivalent to a pin constraint, allowing the sample to rotate around its longitudinal axis. At the same time, the effects of the sample weight are reduced.

Figure 14 Displacements for a voltage equal to $+1,450 \mathrm{~V}$ supplied to the MFC Patches 4, 5 and 6 (second test case)

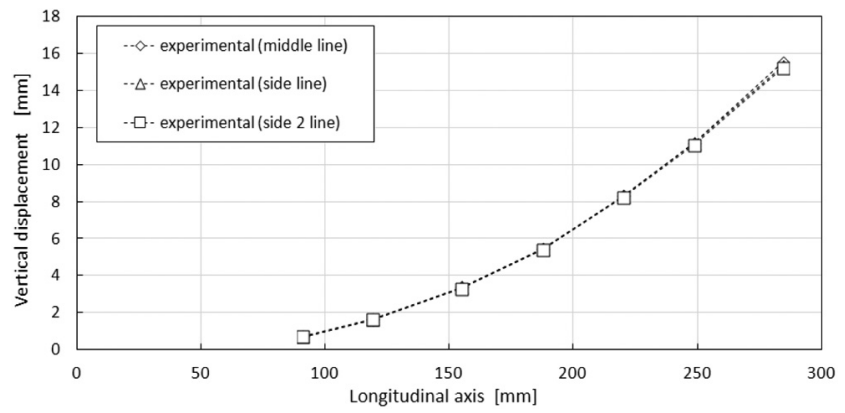

Table IX Displacements measured for a voltage of $+1,450 \mathrm{~V}$ applied to the MFC Patches 4, 5 and 6 (second test case)

\begin{tabular}{|c|c|c|c|}
\hline Point Id & $X[\mathrm{~mm}]$ & $\mathrm{Y}[\mathrm{mm}]$ & $\begin{array}{c}\text { Measured vertical } \\
\text { displacement } \\
\text { [mm] } \\
\text { MFC } 4,5 \text { and } 6 \\
\text { at }+1,450 \mathrm{~V} \\
\text { Channel } 1\end{array}$ \\
\hline 1 & 91 & -10 & 0.700 \\
\hline 2 & 91 & 0 & 0.725 \\
\hline 3 & 91 & 10 & 0.700 \\
\hline 4 & 119 & -10 & 1.625 \\
\hline 5 & 119 & 0 & 1.650 \\
\hline 6 & 119 & 10 & 1.625 \\
\hline 7 & 155 & -10 & 3.300 \\
\hline 8 & 155 & 0 & 3.375 \\
\hline 9 & 155 & 10 & 3.375 \\
\hline 10 & 187.5 & -10 & 5.400 \\
\hline 11 & 187.5 & 0 & 5.425 \\
\hline 12 & 187.5 & 10 & 5.450 \\
\hline 13 & 220 & -10 & 8.225 \\
\hline 14 & 220 & 0 & 8.300 \\
\hline 15 & 220 & 10 & 8.300 \\
\hline 16 & 256 & -10 & 11.05 \\
\hline 17 & 256 & 0 & 11.15 \\
\hline 18 & 256 & 10 & 11.15 \\
\hline 19 & 285 & -10 & 15.25 \\
\hline 20 & 285 & 0 & 15.55 \\
\hline 21 & 285 & 10 & 15.35 \\
\hline
\end{tabular}


Figure $15 \mathrm{~A}$ typical specimen constrained to the testing equipment for torsion tests

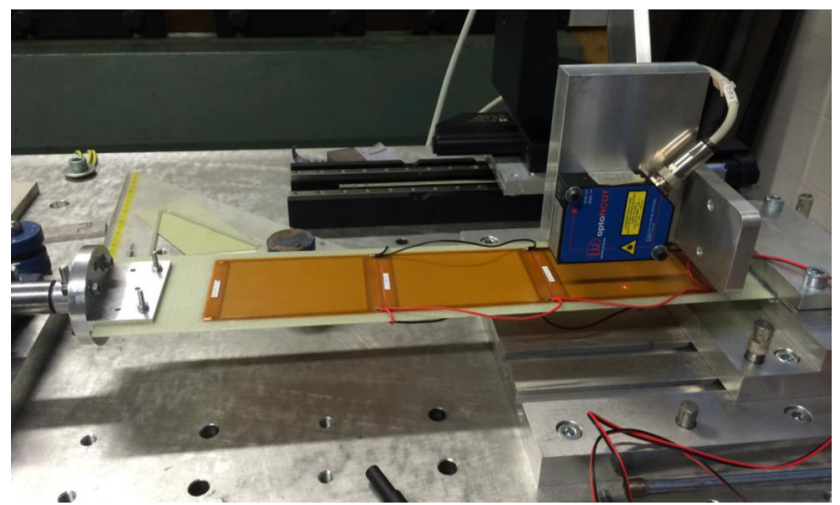

For these kinds of tests, all MFC piezoelectric patches have been loaded at the same time up to a given voltage; this has been done by connecting them in parallel to the first channel of the high-voltage amplifier (Figure 15). Three voltages have been supplied: $-400,+700$ and $+1,400 \mathrm{~V}$. Clearly, negative voltages produce a torsion of the specimen opposite to that produced by positive ones. Figure 16 shows a typical torsion deformation of a glass/epoxy laminated specimen, because of a positive voltage supplied to all MFC patches.

Fourteen measuring points have been chosen to evaluate a deformed shape of the specimen accurately; in particular, seven measurements along the longitudinal axis of the sample (as well as for bending tests), per two in transverse direction. Measurements have been carried out by using two laser optical displacement sensors (Figure 16).

Results of the torsion tests

All torsion specimens have been tested; here, only the results relevant to three testing samples are shown; they refer to two samples made with graphite/epoxy substrate (one having the ply-stacking Sequence 1, the other the Sequence 2), and the sample made with glass/epoxy substrate with the ply-stacking Sequence 1 . Table $\mathrm{X}$ shows the results relevant to a voltage of $+1,400 \mathrm{~V}$ supplied to the MFC piezoelectric patches of the graphite/epoxy torsion Sample 2 with ply-stacking Sequence 2. Figure 17 shows the results for the specimen Sample 2 - Sequence 2 with different voltages level.

In Table $\mathrm{X}$, the coordinates of the measuring points are shown, together with their vertical displacement and the

Figure 16 A typical torsion deformation of a specimen

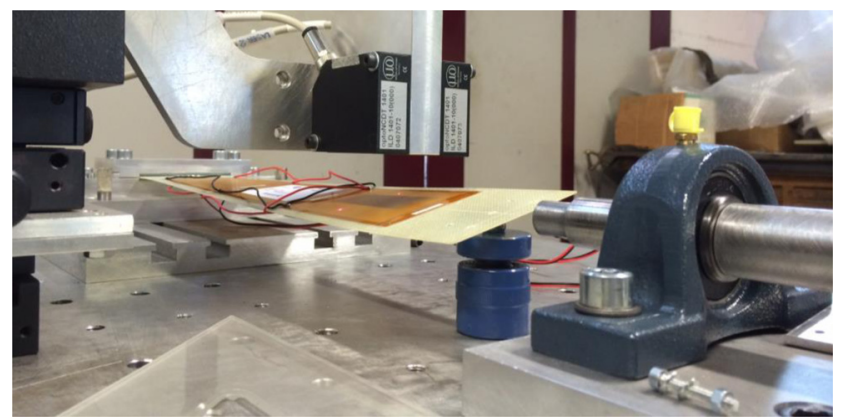

Table X Displacements for a voltage of $+1,400 \mathrm{~V}$ for the MFC patches

\begin{tabular}{ccrcc}
\hline Point Id & $\begin{array}{c}\mathbf{X} \\
{[\mathrm{mm}]}\end{array}$ & $\begin{array}{c}\mathrm{Y} \\
{[\mathrm{mm}]}\end{array}$ & $\begin{array}{c}\text { Measured vertical } \\
\text { displacement } \\
{[\mathrm{mm}]}\end{array}$ & $\begin{array}{c}\text { Angle of } \\
\text { rotation } \\
{[\mathrm{deg}]}\end{array}$ \\
\hline $\mathbf{1}$ & 87 & -20 & 1.325 & 2.94 \\
$\mathbf{2}$ & 87 & 20 & -0.725 & \\
$\mathbf{3}$ & 114 & -20 & 1.875 & 4.36 \\
$\mathbf{4}$ & 114 & 20 & -1.175 & \\
$\mathbf{5}$ & 152 & -20 & 2.475 & 5.99 \\
$\mathbf{6}$ & 152 & 20 & -1.725 & \\
$\mathbf{7}$ & 184.5 & -20 & 3.150 & 7.72 \\
$\mathbf{8}$ & 184.5 & 20 & -2.275 & \\
$\mathbf{9}$ & 217 & -20 & 3.775 & 9.49 \\
10 & 217 & 20 & -2.925 & \\
11 & 255 & -20 & 4.300 & 11.15 \\
12 & 255 & 20 & -3.625 & \\
13 & 282 & -20 & 4.675 & 12.46 \\
14 & 282 & 20 & -4.225 &
\end{tabular}

Note: Graphite/Epoxy Sample 2-Sequence 2

Figure 17 Torsion of the graphite/epoxy Sample 2

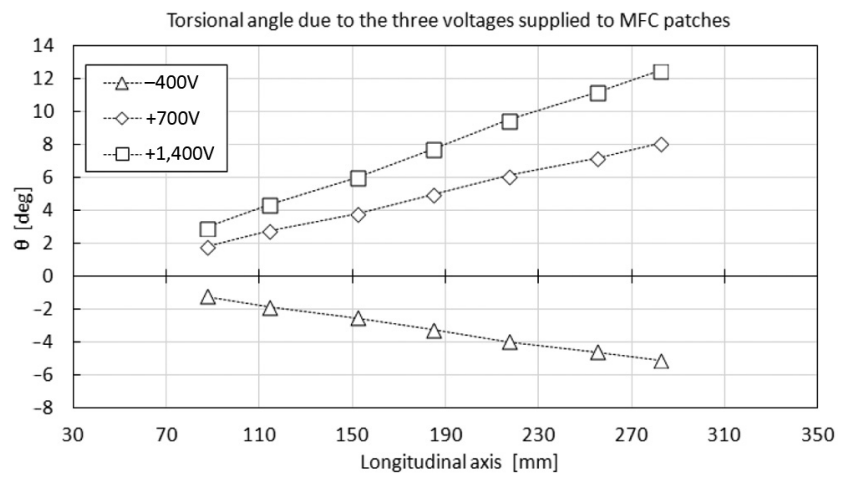

Note: Ply-stacking sequence 2 , voltages $-400,+700$ and $1,400 \mathrm{~V}$

angle of rotation of the sample cross section, where a couple of points lie in. The deformed shape of the specimen has been evaluated as the difference between an initial measured configuration and that measured as a result of the supplied voltage. As shown in the table, for each cross section of the sample, the vertical displacements measured in two points equidistant from the centerline of the sample are different; this is true for all testing specimens, and it is due to the initial deformed shape of a specimen.

Table XI shows the displacements and rotations measured because of voltages equal to $+1,400 \mathrm{~V}$ supplied to the MFC patches of the graphite/epoxy Sample 3 with ply-stacking Sequence 1. By comparing the results of Table X with those of Table XI, it can be observed that the ply-stacking Sequence 1 of the laminated substrate produces a higher shear stiffness than Sequence 2; this is also true for glass/epoxy laminated substrate.

Figure 18 shows the results of tests executed on the torsion specimen graphite/epoxy Sample 3 with ply-stacking Sequence 1 for different voltage levels. 
Table XI Displacements for a voltage of $+1,400 \mathrm{~V}$ for the MFC patches

\begin{tabular}{lcccc}
\hline Point Id & $\begin{array}{c}\mathbf{X} \\
{[\mathrm{mm}]}\end{array}$ & $\mathbf{Y}[\mathrm{mm}]$ & $\begin{array}{c}\text { Measured vertical } \\
\text { displacement [mm] }\end{array}$ & $\begin{array}{c}\text { Angle of } \\
\text { rotation } \\
{[\mathrm{deg}]}\end{array}$ \\
\hline $\mathbf{1}$ & 87 & -20 & 0.725 & 2.08 \\
$\mathbf{2}$ & 87 & 20 & -0.725 & \\
$\mathbf{3}$ & 114 & -20 & 1.050 & 3.11 \\
$\mathbf{4}$ & 114 & 20 & -1.125 & \\
$\mathbf{5}$ & 152 & -20 & 1.375 & 4.19 \\
$\mathbf{6}$ & 152 & 20 & -1.550 & \\
$\mathbf{7}$ & 184.5 & -20 & 1.800 & 5.39 \\
$\mathbf{8}$ & 184.5 & 20 & -1.975 & \\
$\mathbf{9}$ & 217 & -20 & 2.225 & 6.67 \\
10 & 217 & 20 & -2.450 & \\
11 & 255 & -20 & 2.600 & 7.73 \\
12 & 255 & 20 & -2.825 & \\
13 & 282 & -20 & 2.925 & 8.71 \\
14 & 282 & 20 & -3.200 & \\
\hline
\end{tabular}

Note: Graphite/Epoxy Sample 3-Sequence 1

Figure 18 Torsion of the graphite/epoxy Sample 3

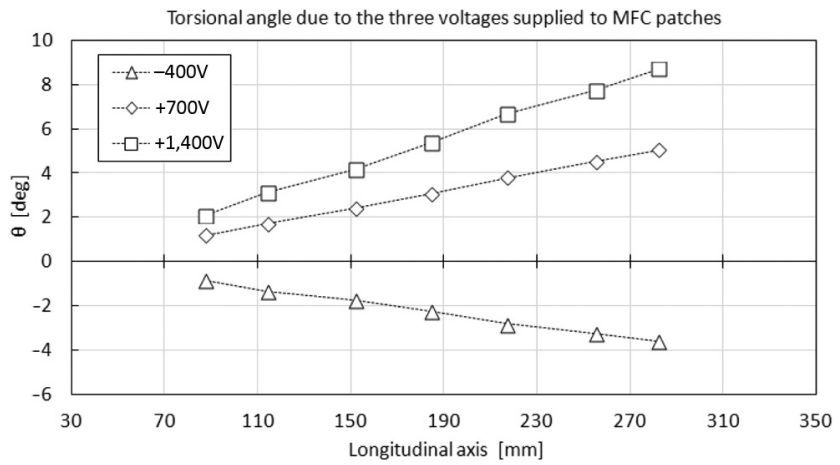

Note: Ply-stacking sequence 1, voltages $-400,+700$ and $1,400 \mathrm{~V}$

Finally, Table XII shows the displacements and rotations measured as a result of voltages equal to $+1,400 \mathrm{~V}$ supplied to the MFC patches of the glass/epoxy Sample 2 with ply-stacking Sequence 1. Figure 19 shows the test results concerning this specimen glass/epoxy Sample 2 with ply-stacking Sequence 1 under different voltage levels.

\section{Comparison between numerical and experimental results}

This section deals with the comparison between the results of FEAs and of the experimental data.

\section{Bending}

The experimental tests regarding the bending behavior concern, at the present state, Sample 1 made up of graphite/ epoxy laminated substrate with ply-staking Sequence 1 (Table I); for this specimen, several test cases have been carried out. They are:

- T1: Bending loading condition due to the specimen's weight.
Table XII Displacements for a voltage of $+1,400 \mathrm{~V}$ for the MFC patches

\begin{tabular}{lcrcc}
\hline Point Id & $\mathbf{X}[\mathrm{mm}]$ & $\mathbf{Y}[\mathrm{mm}]$ & $\begin{array}{c}\text { Measured vertical } \\
\text { displacement }[\mathrm{mm}]\end{array}$ & $\begin{array}{c}\text { Angle of } \\
\text { rotation [deg] }\end{array}$ \\
\hline $\mathbf{1}$ & 87 & -20 & 1.35 & 3.17 \\
$\mathbf{2}$ & 87 & 20 & -0.875 & \\
$\mathbf{3}$ & 114 & -20 & 1.900 & 4.69 \\
$\mathbf{4}$ & 114 & 20 & -1.400 & \\
$\mathbf{5}$ & 152 & -20 & 2.425 & 6.33 \\
$\mathbf{6}$ & 152 & 20 & -2.050 & \\
$\mathbf{7}$ & 184.5 & -20 & 3.075 & 8.16 \\
$\mathbf{8}$ & 184.5 & 20 & -2.725 & \\
$\mathbf{9}$ & 217 & -20 & 3.725 & 9.96 \\
10 & 217 & 20 & -3.400 & \\
11 & 255 & -20 & 4.300 & 11.48 \\
12 & 255 & 20 & -3.975 & 12.98 \\
13 & 282 & -20 & 4.825 & \\
14 & 282 & 20 & -4.600 & \\
Note: & Glass/Epoxy & Sample 2-Sequence 1 & \\
\hline
\end{tabular}

Figure 19 Torsion of the glass/epoxy Sample 2

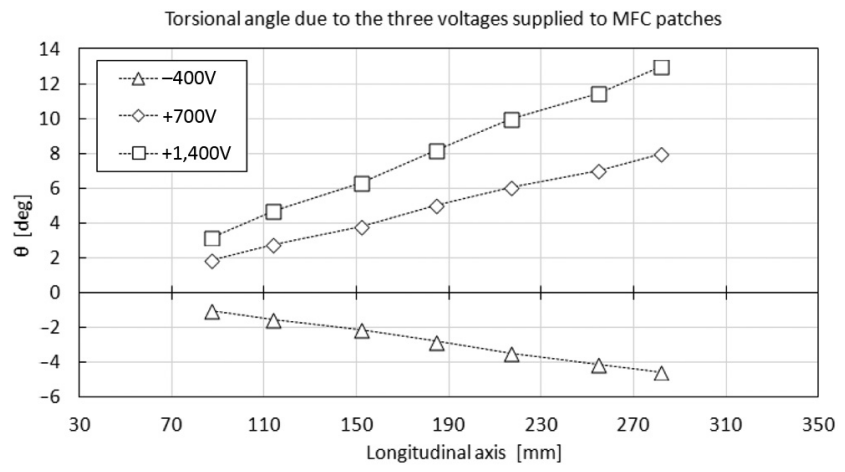

Note: Ply-stacking Sequence 1, voltages $-400,+700$ and $1,400 \mathrm{~V}$

- T2: Bending loading condition due to the maximum positive voltage $(+1,500 \mathrm{~V})$ applied to MFC 4 .

- T3: Bending loading condition due to a voltage applied to MFC 1 and 4.

- T4: Bending loading condition due to a positive voltage equal to $1,450 \mathrm{~V}$ applied to MFC 4, 5 and 6.

In the following, the more interesting results will be shown.

For the T3 case, Figure 20 shows numerical and experimental results obtained by supplying a negative voltage equal to $-250 \mathrm{~V}$ to $\mathrm{MFC} 1$ and a positive one equal to $+750 \mathrm{~V}$ to $\mathrm{MFC} 4$; as can be seen, the numerical curve shows very good agreement with the experimental ones.

For the T4 case, Figure 21 shows numerical and experimental bending curves as a result of a positive voltage equal to $+1,450 \mathrm{~V}$ supplied to the lower MFC piezoelectric patches. For this test, a one-channel amplifier has been used. Also this amplifier is able to supply high voltages. 
Figure 20 Numerical and experimental bending displacements, voltages

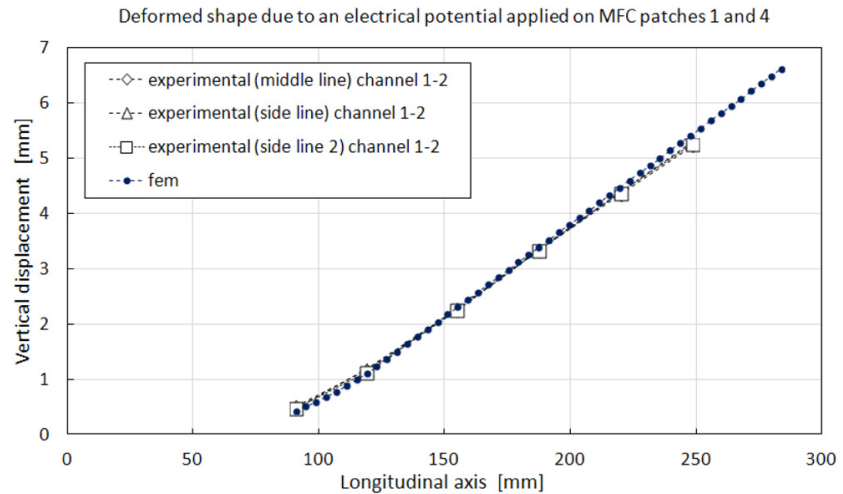

Note: $-250 \mathrm{~V}$ to MFC 1 and $+750 \mathrm{~V}$ to MFC 4

Figure 21 Numerical and experimental bending displacements, voltages

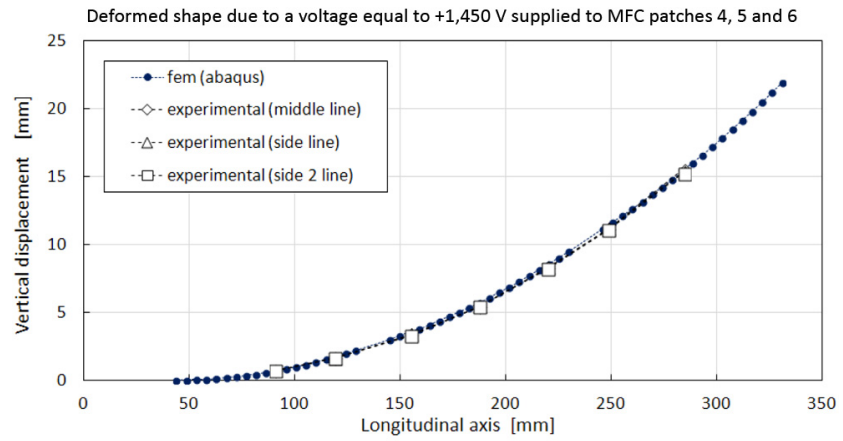

Note: $1,450 \mathrm{~V}$ to the lower MFC patches

As shown, numerical curves are in a very good agreement with the experimental data.

\section{Torsion}

Figure 22 shows the comparison between numerical and experimental curves obtained by supplying the voltages of $-400,+700$ and $+1,400 \mathrm{~V}$ to the graphite/epoxy Sample 2 with ply-stacking Sequence 2 .

Similarly, Figure 23 shows the curves relevant to the graphite/epoxy Sample 3 with ply-stacking Sequence 1, and finally Figure 24 illustrates the curves for the glass/epoxy Sample 2 with ply-stacking Sequence 2.

As shown, numerical results are in a good agreement with the experimental data.

\section{Conclusion}

Within a research project funded by the European Commission, a theoretical study devoted to the design of simple coupons made up of composite materials and MFC patches has been carried out. The geometry of the specimens has been defined to evaluate the bending and torsional behavior of such a hybrid material. The MFC are made of piezoelectric fibers and thus they have directional functionality.
Figure 22 Comparison of numerical and experimental data

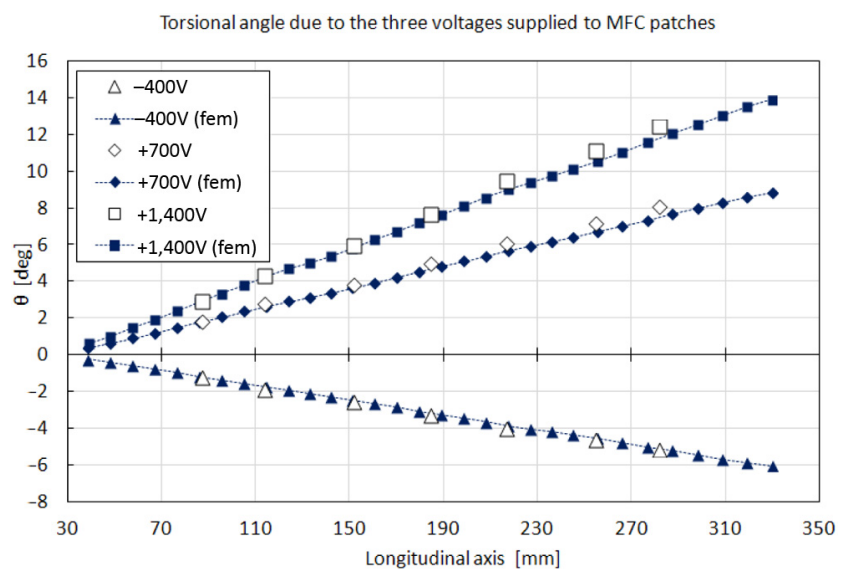

Note: Graphite/epoxy sample 2 - sequence 2

Figure 23 Comparison of numerical and experimental data

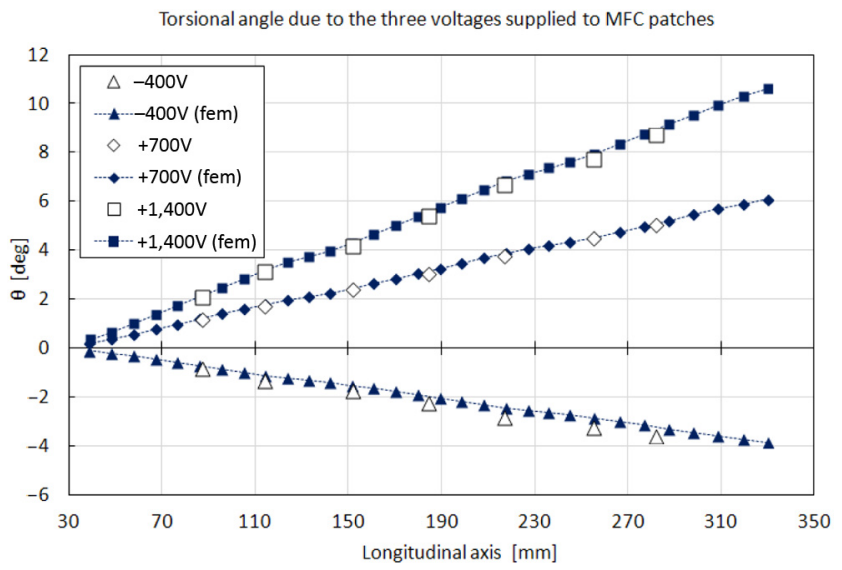

Note: Graphite/epoxy sample 3 - sequence 1

Figure 24 Comparison of numerical and experimental data

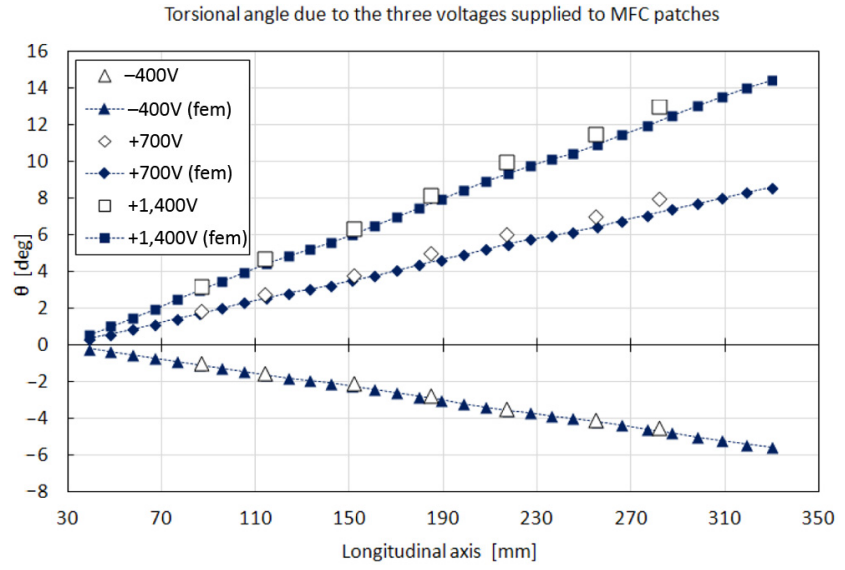

Note: Glass/epoxy sample 2 - sequence 1 
Numerical and experimental tests on hybrid specimens have been carried out with the aim to assess their structural behavior when a voltage is supplied to the MFC piezoelectric patches; in particular, bending and torsion deformation have been investigated.

The novel series of tests, that have been performed in the present research, have been conceived to validate the numerical procedures used to model the piezoelectricity; the results of the FEAs have shown very good agreement with the experimental data. For this reason, in the next step of the project, a reliable numerical procedure will be adopted to design a more complex hybrid structure.

In fact, further work will focus on the development of a small-scale model of self-shaping boxed structures (that is models of a bay of a slender wing box) manufactured with the same technology used for the hybrid specimens analyzed and tested in the present research. Such boxed structures will allow the simulation, in a reduced scale, of the active portion of a futuristic wing structure.

\section{References}

Bilgen, O., Friswell, M.I., Kochersberger, K.B. and Inman, D.J. (2011), "Surface actuated variable-camber and variable-twist morphing wings using piezocomposites", 52nd AIAA/ASME/ASCE/AHS/ASC Structures, Structural Dynamics and Materials, Denver, CO, April.

Binette, P., Dano, M.L. and Gendron, G. (2009), "Active shape control of composite structures under thermal loading", Smart Materials and Structures, Vol. 18 No. 2, p. 12, Article ID 025007.

Chesne, S., Jean-Mistral, C. and Gaudiller, L. (2013), "Experimental identification of smart material coupling effects in composites structures", Smart Materials and Structures, Vol. 22 No. 7, p. 10, Article ID 075007.

Dassault Systemes (2013), "Simulia - ABAQUS 6.11 user's guide", available at: www.simulia.com

Henslee, I.A., Miller, D.A. and Tempero, T. (2012), "Fatigue life characterization for piezoelectric macrofiber composites", Smart Materials and Structures, Vol. 21 No. 1, p. 7, Article ID 105037.

Krempel GmbH (2014), "Prepegs-System BX", available at: www.krempel-group.com

Li, S., Huang, L., Jiang, L. and Qin, R. (2014), "A bidirectional B-spline finite point method for the analysis of piezoelectric laminated composite plates and its application in material parameter identification", Composite Structures, Vol. 107 No. 1, pp. 346-362.

Molinari, G., Quack, M., Arrieta, A.F., Morari, M. and Ermanni, P. (2015), "Design, realization and structural testing of a compliant adaptable wing", Smart Materials and Structures, Vol. 24 No. 10, p. 20, Article ID 105027.

Morisghima, R., Guo, S. and Ahmed, S. (2010), "A composite wing with a morphing leading edge", 51st AIAA/ ASME/ASCE/AHS/ASC Structures, Structural Dynamics and Materials, Orlando, FL, April.

National Instruments (2013), "LabVIEW 2012 user's guide", available at: www.ni.com/labview

Paradies, R. and Ciresa, P. (2009), "Active wing design with integrated flight control using piezoelectric macro fiber composites", Smart Materials and Structures, Vol. 18 No. 1, p. 9, Article ID 035010.

Rao, M.N., Tarun, S., Schmidt, R., Morari, M. and Schröder, K.U. (2016), "Finite element modelling and analysis of piezo-integrated composite structures under large applied electric fields", Smart Materials and Structures, Vol. 25 No. 5, p. 12, Article ID 055044.

Riemenschneider, J., Keye, S., Wierach, P. and Mercier des Rochettes, H. (2004), "Overview of the common DLR/ ONERA project 'Active twist blade' (ATB)", 30th European Rotorcraft Forum, Marseilles, September.

Sathyanarayana, C.N., Raja, S. and Ragavendra, H.M. (2013), "Procedure to use PZT sensors in vibration and load measurements", Smart Materials Research, Vol. 2013, p. 9, Article ID 173605.

Schröck, J., Meurer, T. and Kugi, A. (2011a), "Control of a flexible beam actuated by macro-fiber composite patches: I, Modeling and feed forward trajectory control", Smart Materials and Structures, Vol. 20 No. 1, p. 7, Article ID 015015.

Schröck, J., Meurer, T. and Kugi, A. (2011b), "Control of a flexible beam actuated by macro-fiber composite patches: II, Hysteresis and creep compensation, experimental results", Smart Materials and Structures, Vol. 20 No. 1, p. 10, Article ID 015016.

Smart Material Corporation (2013), available at: www.smartmaterial.com

\section{Corresponding author}

Mario Rosario Chiarelli can be contacted at: chiarelli@ing.unipi.it 